\title{
Verification Study of Residual Activity Measurements After Yttrium-90 Radioembolization with Glass Microspheres
}

\author{
S. C. Ebbers ${ }^{1}$ (D) B. Kunnen ${ }^{1}$ - B. J. van Nierop ${ }^{1}$ - J. L. M. Bemelmans ${ }^{1}$ \\ G. C. Krijger ${ }^{1}$ - M. G. E. H. Lam ${ }^{1}$ - A. J. A. T. Braat ${ }^{1}$
}

Received: 6 January 2020 / Accepted: 23 April 2020/Published online: 20 May 2020

(C) The Author(s) 2020

\begin{abstract}
Objective After yttrium-90 $\left({ }^{90} \mathrm{Y}\right)$ radioembolization, residual activity and its consequences for dosimetric calculations are often not reported. The manufacturer for glass microspheres prescribes standard residual activity measurements by a survey meter, but the validity lacks evidence. This study aims to verify the accuracy of the survey meter approach for measuring residual activity of glass microspheres after treatment with glass microspheres.

Methods To validate the accuracy of the survey meter approach, the measured residual activity of glass microspheres by survey meter was compared with measurements by PET. A sample of these waste containers was also measured by dose calibrator to confirm the accuracy of the PET.

Results Twenty-four waste containers from glass microsphere treatments were prospectively scanned with ${ }^{90} \mathrm{Y}$ PET/CT. Bland-Altman plots showed substantial disagreement in residual activity measured by survey meter versus the residual activity measured by PET and dose calibrator, whereas the correlation between PET and dose calibrator was excellent $(\rho=0.99)$.

Conclusion This study found a significant disagreement between the residual activities measured by the survey meter, compared to measurements by PET and dose calibrator. If relatively high amounts of residual activity are encountered using the exposure rate measurement with a survey meter, additional quantification should be
\end{abstract}

S. C. Ebbers

s.c.ebbers-2@umcutrecht.nl

1 Department of Radiology and Nuclear Medicine, University Medical Center Utrecht, Heidelberglaan 100, 3508 GA Utrecht, The Netherlands considered using either PET/CT or a dose calibrator measurement.

Keywords Yttrium-90 microsphere ·

Radioembolization · SIRT · TheraSphere · Residual activity · Survey meter

\section{Introduction}

Selective internal radiotherapy (SIRT), also known as radioembolization, has proved to be an effective and safe treatment for various primary and secondary liver tumors [1-5]. Yttrium-90 $\left({ }^{90} \mathrm{Y}\right)$ is the most commonly used isotope and its decay is mainly $\beta^{-}$radiation, but 32 out of every one million decays are accompanied by positron emission, allowing PET-based quantification [6-8]. Accurate dosimetry is important, as several studies suggest a doseresponse relationship [9-14]. However, there is little reported on the amount of residual activity (RA) in the administration system after administration and its consequences on treatment dosimetry [15]. For glass microspheres (TheraSphere ${ }^{\circledR}$, Biocompatibles UK Ltd), the method of measuring RA recommended by the manufacturer is by exposure rate measurements (ERM) [16]. This method may be inaccurate, due to the differing geometry of the waste material. Two other widely available methods of measuring the RA are ${ }^{90} \mathrm{Y}-\mathrm{PET} / \mathrm{CT}$ or a dose calibrator. Both methods are less likely to be influenced by the geometry of the material and thus expected to be more accurate. This study aims to verify the best quantitative method for measuring RA. 


\section{Methods}

\section{Procedures et al. [17]}

Pre-treatment imaging and SIRT were performed using the procedures as previously described by Padia et al. [17]. Therapeutic activity was calculated according to the commonly used medical internal radiation dose (MIRD) method. After administration of the microspheres, the microcatheter, tubing, disposable surgical towel, gloves and V-vial (= vial containing therapeutic activity) were stored in one waste container for each injection. From August until October 2017, all waste containers from glass microsphere treatments were collected. All RA measurements were corrected for background activity and decay corrected to the date and time of microsphere administration.

\section{Survey Meter Method}

ERM and RA calculation were performed using the calibration sheet and calculation method provided by the manufacturer (Fig. 1). In addition to the manufacturer's instruction, the exposure rates were measured three times per side, being the 12, 3, 6 and 9 o'clock sides, giving a total of twelve ERM per item and a more precise mean ERM.

\section{${ }^{90} Y-P E T / C T$}

To confirm the accuracy of PET/CT, two unused vials of glass microspheres with a known calibrated activity (14 and $8 \mathrm{GBq}$ ) were scanned at multiple time points until decay had dropped below $5 \mathrm{MBq}$. All waste containers were scanned with PET/CT (Siemens Biograph mCT time of flight system; Siemens Healthcare, Erlangen, Germany) within $36 \mathrm{~h}$ after treatment. Acquisition included $10 \mathrm{~min}$ per PET position with approx. $43 \%$ overlap for entire field of view. PET images were reconstructed using 4 iterations with 21 subsets, a $5 \mathrm{~mm}$ full width at half maximum Gaussian post-reconstruction filter and reconstructed voxel size of $4.1 \times 4.1 \times 3.0 \mathrm{~mm}^{3}$. A co-registered CT scan was made for attenuation correction and to visualize the location of RA within the waste container. The waste container and V-vial were manually segmented, and activity recovery in each segmentation was calculated (ImageJ). By

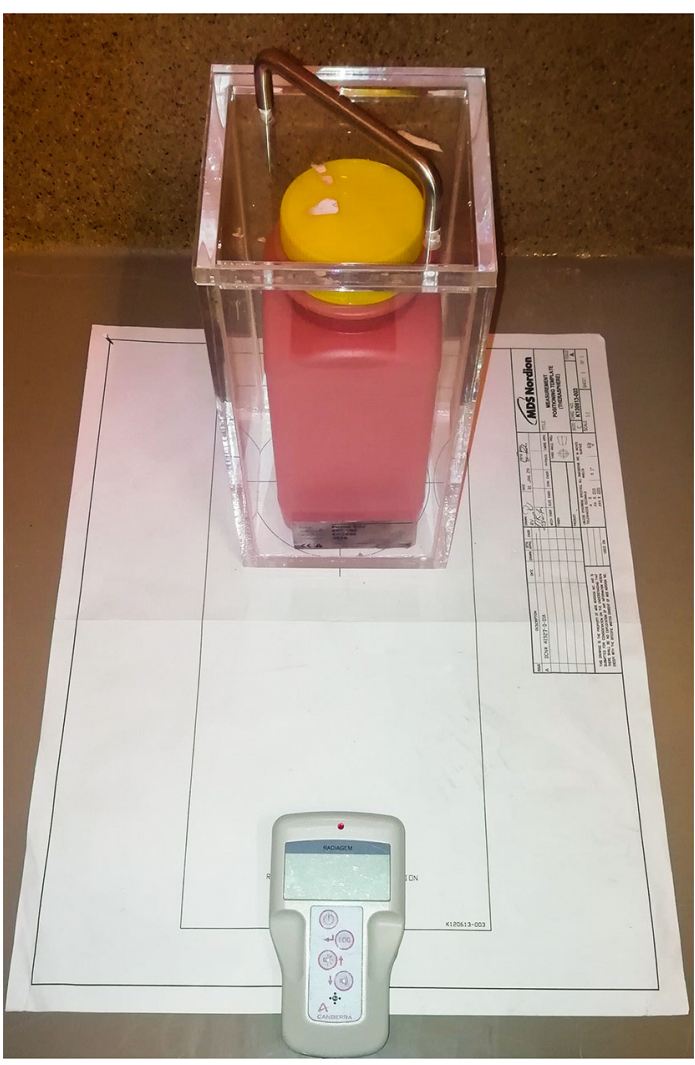

Fig. 1 Exposure rate of each waste container was measured with a dose rate and survey meter (Radiagem ${ }^{\mathrm{TM}}$ 2000, Canberra). The fraction of residual activity was based on the mean exposure rate of the V-vial before treatment and the waste container after treatment, measured three times from all four sides. This fraction was multiplied by the calibrated activity provided by the supplier, resulting in the residual activity. No perspex shielding was used; however, to correct for the absence of perspex shielding a representable sample of waste containers was measured with and without shielding. Using simple linear regression, a correction factor was applied to all measurements

subtracting the $\mathrm{V}$-vial segmentation from the entire waste container, the RA in the tubing system could be calculated.

\section{Dose Calibrator}

In a subset, waste material was measured using the dose calibrator (VDC-404, Veenstra Instruments, The Netherlands) within $48 \mathrm{~h}$ after treatment. Waste material was introduced into the dose calibrator in two separate parts, so that it would be sufficiently surrounded by the perspex shielding of the dose calibrator. 


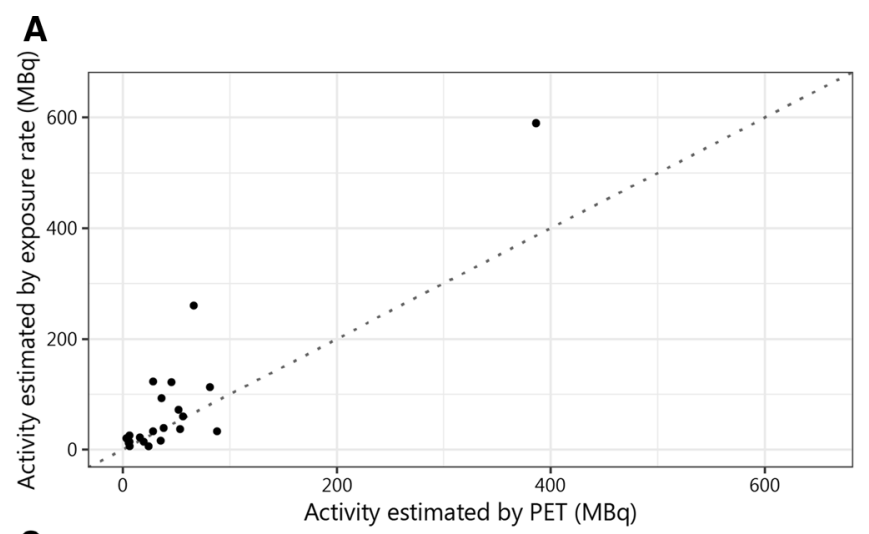

B
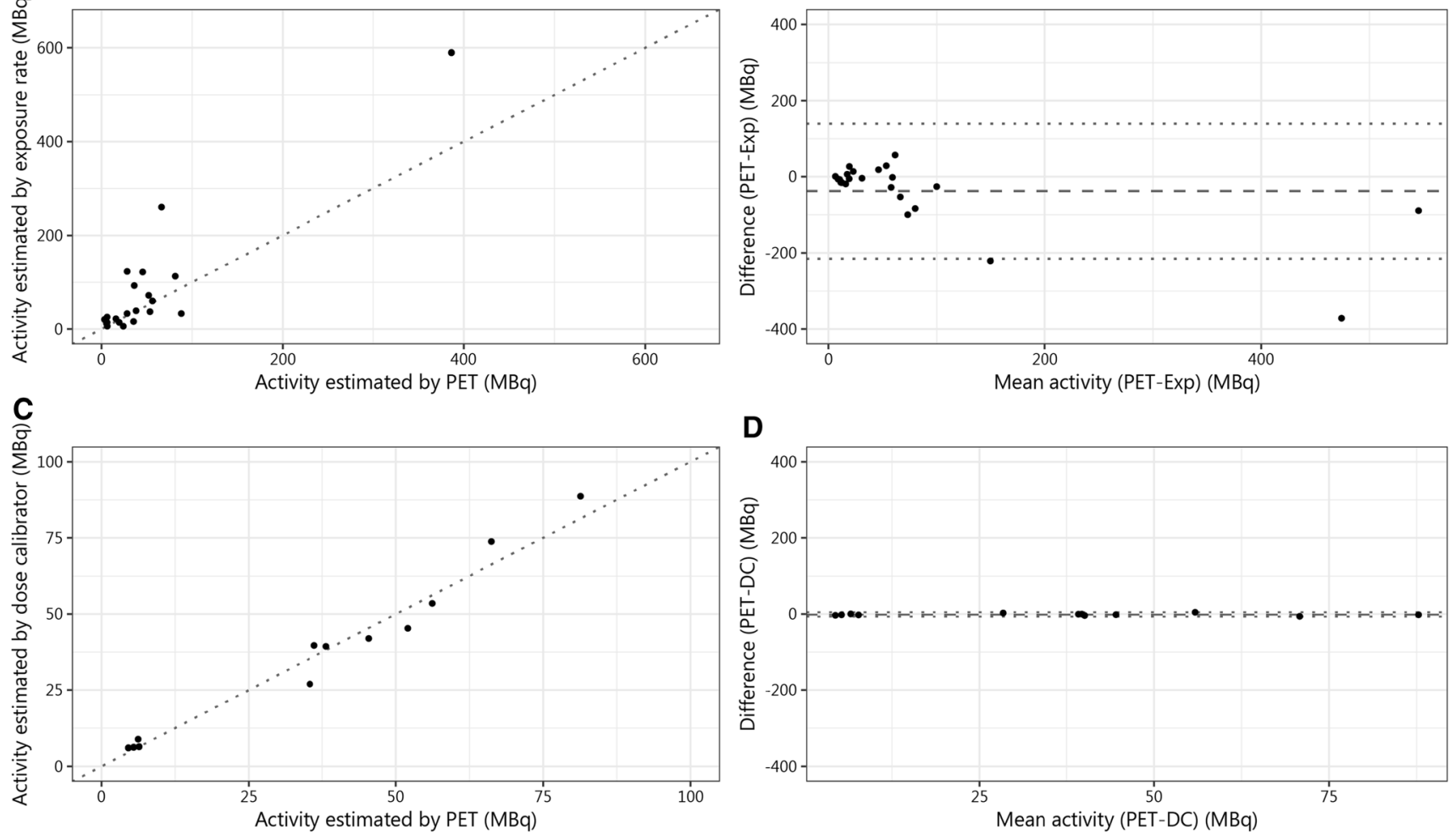

D

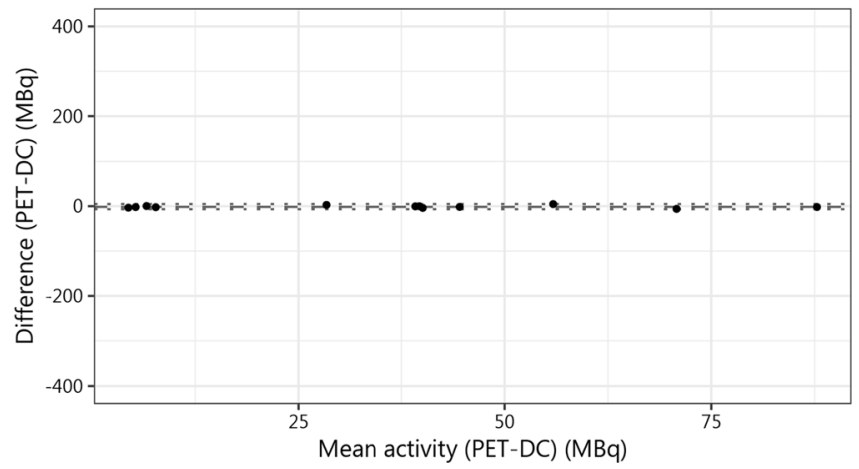

Fig. 2 A correlation between residual activity measured by PET and exposure rate in $\mathrm{MBq}$ (megabecquerel). B Bland-Altman plot showing the level of agreement between measurements by PET and survey meter. C correlation between measurement of residual

\section{Data Analysis}

activities by PET and dose calibrator. D Bland-Altman plot showing level of agreement between measurements with PET and dose calibrator

\section{Results}

All data analyses were performed using $\mathrm{R}$ version 3.5.2. The validity of ERM was measured by performing a twosided paired samples t-test on the ERM and the PET measurements. A subset was also measured by dose calibrator, for which additional t-tests were performed. To better understand the agreement between the three methods of measurement, Bland-Altman plots were used [18]. Correlation of findings was performed using Spearman's rank correlation coefficient. Findings were deemed statistically significant with a $p$-value $<0.05$.

Activity measurement of the two unused vials of glass microspheres by PET/CT correlated with calculated physical decay as long as the scanned activity was larger than $15 \mathrm{MBq}$. In total, twenty-four waste containers were scanned with PET/CT after the ERM. Twelve waste containers were also measured in the dose calibrator, after ERM and PET/CT.

Of the 24 waste containers, the median calibrated activity before administration was $1933 \mathrm{MBq}$ (range [189; 10,100]). The median ERM was $0.61 \mu \mathrm{Sv} / \mathrm{h}$ (IQR [0.36; 1.91]). The estimated median RA was $33 \mathrm{MBq}$ (IQR [18; 98]) based on ERM and $32 \mathrm{MBq}$ (IQR [6; 54]) based on 


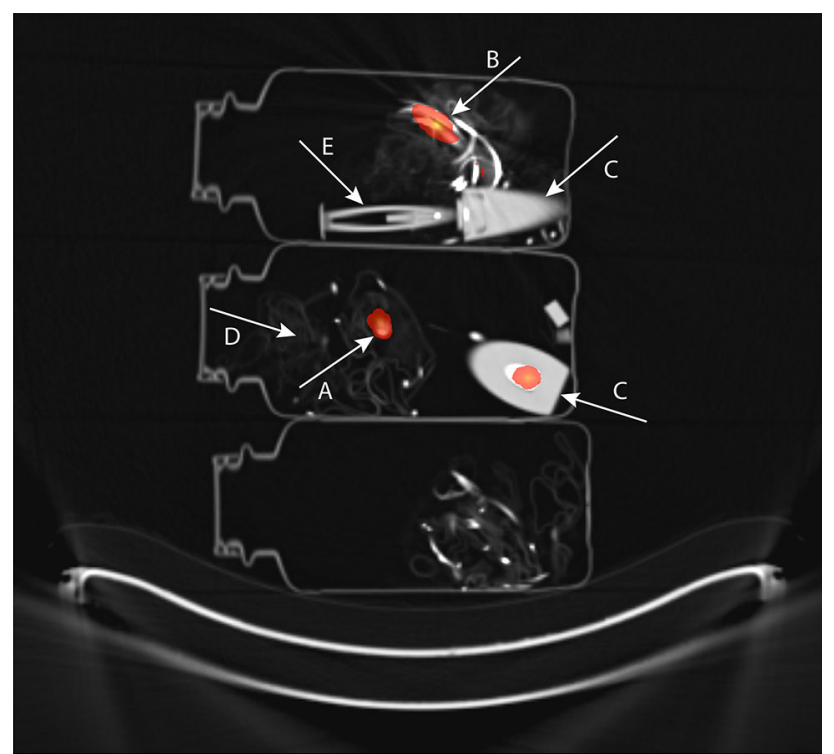

Fig. 3 Combined images of PET and CT of three of the waste containers after radioembolization with glass microspheres showing that residual activity was found in the microcatheter connector (A), tubing (B) and V-vial (C). Other items that can be distinguished are the surgical cloth (D) and the plunger $(\mathbf{E}) .{ }^{89} \mathrm{Zr}$ was used as an alternative isotope for acquisition and reconstruction (as ${ }^{90} \mathrm{Y}$ as acquisition isotope was not available at that time). Activity recovery was corrected for the different half-life and positron branching ratio between ${ }^{89} \mathrm{Zr}$ and ${ }^{90} \mathrm{Y}$

PET/CT. According to the Bland-Altman plots, there was substantial disagreement between the measurements (Fig. 2) and rather low correlation ( $\rho=0.76, p<0.001)$. The paired samples t-test showed a significant mean difference between both measurements of $41 \mathrm{MBq}(95 \% \mathrm{CI}$ [5; 77], $p<0.05)$.

The correlation between the 12 measurements of PET and dose calibrator was much higher $(\rho=0.99$, $p<0.001$ ). The mean difference based on PET (median = $37 \mathrm{MBq}$; IQR $[6 ; 53]$ ) did not differ from the dose calibrator (median $=40 \mathrm{MBq}$; IQR $[8 ; 47]), \mathrm{p}=0.850$.

$90 \%$ of RA was located outside the V-vial, and $10 \%$ was located inside the V-vial. Visually, most of the RA was located in the connector between tubing and microcatheter (Fig. 3). Only in one waste container, RA in the V-vial was $>1 \%$.

\section{Discussion}

This study shows that ERM of RA by survey meter is inaccurate and generally results an overestimation, especially in case of larger amounts of RA, as the absolute measurement error becomes more significant. Additionally, RA is mainly located in the connector of the microcatheter and not in the V-vial itself (Fig. 3).

The primary goal of measuring RA is to check whether a complete infusion was accomplished. Since ${ }^{90} \mathrm{Y}$ is a pure beta emitter, the dose rate measurement relies on the measurement of bremsstrahlung, which is highly influenced by differences in geometry. The resulting inaccuracies do slightly impair the detection of small amounts of RA. However, when higher exposure rates are measured, a better estimate of the RA can be obtained by PET/CT or dose calibrator measurements.

A limitation of this study is that not all waste containers were also measured in the dose calibrator. This approach was chosen to limit potential radiation exposure to laboratory workers.

Studies on radioembolization tend to publish values of pre-treatment calculated or calibrated activities, without correcting for RA [19]. A more evidence-based and standardized approach for RA measurement and correction are needed for comparability in the literature. Each method of measurement has advantages and disadvantages (Table 1).

Based on our results, we recommend the use of PET or dose calibrator measurements to calculate and report RA in patients treated with SIRT, for whom RA $>50 \mathrm{MBq}$ was found by exposure rate measurements. As an alternative, multiple studies demonstrated the usefulness of calculating the total absorbed dose based on the post-treatment PET/ CT scans; however, this might be time-consuming and

Table 1 Overview of advantages and disadvantages of measurements of residual activity after ${ }^{90} \mathrm{Y}$ radioembolization

\begin{tabular}{|c|c|c|}
\hline Method & Advantages & Disadvantages \\
\hline Survey meter & Little radiation exposure and low costs & Inaccurate in case of high residual activities \\
\hline $\begin{array}{l}\text { Dose } \\
\text { calibrator }\end{array}$ & Most accurate measurement and low costs & $\begin{array}{l}\text { High risk of contamination and additional radiation exposure to } \\
\text { laboratory workers }\end{array}$ \\
\hline $\mathrm{PET} / \mathrm{CT}$ & $\begin{array}{l}\text { Very accurate measurement and little radiation } \\
\text { exposure }\end{array}$ & Not available in all centers or costly \\
\hline
\end{tabular}


acquiring post-treatment ${ }^{90} \mathrm{Y}$-PET-CT might not be local clinical practice [20-22]. Finally, because of the retention of glass microspheres in the connector of the microcatheter, we emphasize the importance of thorough flushing and, after administration, the microcatheter should not be disconnected upon disposal to avoid contaminating the angiography suite.

\section{Conclusion}

This study found a significant disagreement between the residual activities measured by the survey meter, compared to measurements by PET and dose calibrator. If relatively high amounts of residual activity are encountered using the exposure rate measurement with a survey meter, additional quantification by PET/CT or dose calibrator should be considered.

Funding This study was not supported by any funding.

\section{Compliance with Ethical Standards}

Conflict of interest The authors declare that they have no conflict of interest.

Human and Animal Rights All procedures performed in studies involving human participants were in accordance with the ethical standards of the institutional and/or national research committee and with the 1964 Helsinki Declaration and its later amendments or comparable ethical standards. For this type of study, formal consent is not required.

Informed Consent For this type of study, informed consent is not required.

Consent for Publication For this type of study, consent for publication is not required.

Open Access This article is licensed under a Creative Commons Attribution 4.0 International License, which permits use, sharing, adaptation, distribution and reproduction in any medium or format, as long as you give appropriate credit to the original author(s) and the source, provide a link to the Creative Commons licence, and indicate if changes were made. The images or other third party material in this article are included in the article's Creative Commons licence, unless indicated otherwise in a credit line to the material. If material is not included in the article's Creative Commons licence and your intended use is not permitted by statutory regulation or exceeds the permitted use, you will need to obtain permission directly from the copyright holder. To view a copy of this licence, visit http://creativecommons. org/licenses/by/4.0/.

\section{References}

1. Kennedy AS, Ball D, Cohen SJ, et al. Multicenter evaluation of the safety and efficacy of radioembolization in patients with unresectable colorectal liver metastases selected as candidates for
90Y resin microspheres. J Gastrointest Oncol. 2015;6(2):134-42. https://doi.org/10.3978/j.issn.2078-6891.2014.109.

2. Maleux G, Deroose C, Laenen A, et al. Yttrium-90 radioembolization for the treatment of chemorefractory colorectal liver metastases: technical results, clinical outcome and factors potentially influencing survival. Acta Oncol. 2016;55(4):486-95. https://doi.org/10.3109/0284186X.2015.1101151.

3. Peker A, Çiçek O, Soydal Ç, Küçük NÖ, Bilgiç S. Radioembolization with yttrium-90 resin microspheres for neuroendocrine tumor liver metastases. Diagn Interv Radiol. 2015;21(1):54-9. https://doi.org/10.5152/dir.2014.14036.

4. Salem R, Thurston KG. Radioembolization with Yttrium-90 microspheres: a state-of-the-art brachytherapy treatment for primary and secondary liver malignancies. J Vasc Interv Radiol. 2006;17(10):1571-93. https://doi.org/10.1097/01.RVI. 0000236744.34720 .73 .

5. Hickey R, Lewandowski RJ, Prudhomme T, et al. Y90 Radioembolization of colorectal hepatic metastases using glass microspheres: safety and survival outcomes from a 531-patient multicenter study. J Nucl Med. 2015;57(5):665-71. https://doi. org/10.2967/jnumed.115.166082.

6. Selwyn RG, Nickles RJ, Thomadsen BR, DeWerd LA, Micka JA. A new internal pair production branching ratio of $90 \mathrm{Y}$ : the development of a non-destructive assay for $90 \mathrm{Y}$ and $90 \mathrm{Sr}$. Appl Radiat Isot. 2007;65(3):318-27. https://doi.org/10.1016/j. apradiso.2006.08.009.

7. Gates VL, Esmail AAH, Marshall K, Spies S, Salem R. Internal pair production of $90 \mathrm{Y}$ permits hepatic localization of microspheres using routine PET: proof of concept. J Nucl Med. 2011;52(1):72-6. https://doi.org/10.2967/jnumed.110.080986.

8. Greenberg JS, Deutsch M. Positrons from the decay of P32 and Y90. Phys Rev. 1956;102(2):415-21. https://doi.org/10.1103/ PhysRev.102.415.

9. Eaton BR, Kim HS, Schreibmann E, et al. Quantitative dosimetry for yttrium-90 radionuclide therapy: tumor dose predicts fluorodeoxyglucose positron emission tomography response in hepatic metastatic melanoma. J Vasc Interv Radiol. 2014;25(2):288-95. https://doi.org/10.1016/j.jvir.2013.08.021.

10. Flamen P, Vanderlinden B, Delatte $P$, et al. Multimodality imaging can predict the metabolic response of unresectable colorectal liver metastases to radioembolization therapy with Yttrium-90 labeled resin microspheres. Phys Med Biol. 2008;53(22):6591-603. https://doi.org/10.1088/0031-9155/53/22/ 019.

11. van den Hoven AF, Rosenbaum CENM, Elias SG, et al. Insights into the dose-response relationship of radioembolization with resin 90y-microspheres: a prospective cohort study in patients with colorectal cancer liver metastases. J Nucl Med. 2016;57(7):1014-9. https://doi.org/10.2967/jnumed.115.166942.

12. Mazzaferro V, Sposito C, Bhoori S, et al. Yttrium-90 radioembolization for intermediate-advanced hepatocellular carcinoma: a phase 2 study. Hepatology. 2013;57(5):1826-37. https://doi.org/ 10.1002/hep.26014.

13. Demirelli S, Erkilic M, Oner AO, et al. Evaluation of factors affecting tumor response and survival in patients with primary and metastatic liver cancer treated with microspheres. Eur J Gastroenterol Hepatol. 2015;36(4):340-9. https://doi.org/10. 1097/MNM.0000000000000257.

14. Garin E, Rolland Y, Campillo-Gimenez B, Edeline J. Negative phase 3 study of $90 \mathrm{Y}$ microspheres versus sorafenib in HCC. Lancet Oncol. 2018;19(2):e70. https://doi.org/10.1016/S14702045(18)30024-X.

15. Hoang NS, Khalaf MH, Rosenberg JK, et al. Quantification of activity lost to delivery-system residual and decay in Yttrium-90 radioembolization. J Vasc Interv Radiol. 2018;1:6. https://doi. org/10.1016/j.jvir.2018.07.011. 
16. Biocompatibles UK Ltd. Package Insert - TheraSphere ${ }^{\circledR}$ Yttrium-90 Glass Microspheres - Rev. 14.; 2014. https://www. btg-im.com/BTG/media/TheraSphere-Documents/PDF/

TheraSphere-Package-Insert_USA_Rev-14.pdf. Accessed October 26, 2017.

17. Padia SA, Lewandowski RJ, Johnson GE, et al. Radioembolization of hepatic malignancies: background, quality improvement guidelines, and future directions. $\mathrm{J}$ Vasc Interv Radiol. 2017;28(1):1-15. https://doi.org/10.1016/j.jvir.2016.09.024.

18. Bland JM, Altman DG. Statistical methods for assessing agreement between two methods of clinical measurement. Lancet. 1986;327(8476):307-10

19. Jha AK, Mithun S, Purandare NC, et al. Impact of the activity calculation method used in transarterial radioembolization. Nucl Med Commun. 2016;37(9):917-23. https://doi.org/10.1097/ MNM.0000000000000544.

20. Srinivas SM, Natarajan N, Kuroiwa J, et al. Determination of radiation absorbed dose to primary liver tumors and normal liver tissue using post-radioembolization 90Y PET. Front Oncol. 2014;4:255. https://doi.org/10.3389/fonc.2014.00255.

21. Lea WB, Tapp KN, Tann M, Hutchins GD, Fletcher JW, Johnson MS. Microsphere localization and dose quantification using positron emission tomography/CT following hepatic intraarterial radioembolization with yttrium-90 in patients with advanced hepatocellular carcinoma. J Vasc Interv Radiol. 2014;25(10):1595-603. https://doi.org/10.1016/j.jvir.2014.06. 028.

22. D'Arienzo M, Chiaramida P, Chiacchiararelli L, et al. 90Y PETbased dosimetry after selective internal radiotherapy treatments. Nucl Med Commun. 2012;33(6):633-40. https://doi.org/10.1097/ MNM.0b013e3283524220.

Publisher's Note Springer Nature remains neutral with regard to jurisdictional claims in published maps and institutional affiliations. 